\title{
Thrombus straddling a patent foramen ovale, pulmonary embolism and paradoxical embolism: a rare trifecta
}

\author{
Rachel Dada, ${ }^{1}$ Jafar Dada, ${ }^{1}$ Murad Abdelsalam, ${ }^{2}$ Yashwant Agrawal ${ }^{2}$
}

'Internal Medicine, St Joseph Mercy Oakland, Pontiac, Michigan, USA

${ }^{2}$ Cardiology, St Joseph Mercy Oakland Hospital, Pontiac, Michigan, USA

\section{Correspondence to} Dr Yashwant Agrawal, yashwantagrawal.agrawal@ gmail.com

Accepted 20 September 2018

\section{DESCRIPTION}

A 55-year-old male presented to the emergency room after awakening with left facial droop, leftsided weakness and garbled speech. Vitals were significant for hypotension $(73 / 43 \mathrm{~mm} \mathrm{Hg}$ ) and hypothermia $\left(35.3^{\circ} \mathrm{C}\right)$. Physical examination was significant for left facial droop, dysarthria, bilateral upper extremity strength $4 / 5$, bilateral lower extremity strength $3 / 5$. Laboratory tests were significant for leucocytosis of $16.9 \times 10^{9} / \mathrm{L}$ thou $/ \mathrm{mcL}$, lactic acid $2.5 \mathrm{mmol} / \mathrm{L}$, creatinine $3.07 \mathrm{mg} / \mathrm{dL}$ and troponin $0.07 \mathrm{ng} / \mathrm{mL}$.

Chest X-ray revealed no acute process. Head CT revealed no acute process with old right basal ganglia and right frontal lobe infarcts. Head and neck magnetic resonance angiography (MRA) revealed no blockages or aneurysmal dilatations. Brain MRI revealed three areas of diffusion restriction in left temporal occipital lobe, compatible with acute infarcts. Tissue plasminogen activator was not given since he was outside the window. Stroke work-up was ordered, pancultures were sent, broad-spectrum antibiotics were started, and he was sent to the intensive care unit.

Transthoracic echocardiogram (TTE) revealed an ejection fraction of $55 \%-60 \%$, and a positive bubble study. A transoesophageal echocardiogram revealed a grade 4 patent foramen ovale ( $\mathrm{PFO}$ ) with bidirectional shunting. Closure was recommended. Venous Duplex of bilateral lower extremities demonstrated acute occlusive deep venous thrombosis of the right superficial femoral, popliteal, posterior tibial and peroneal veins, hence a heparin drip was started.

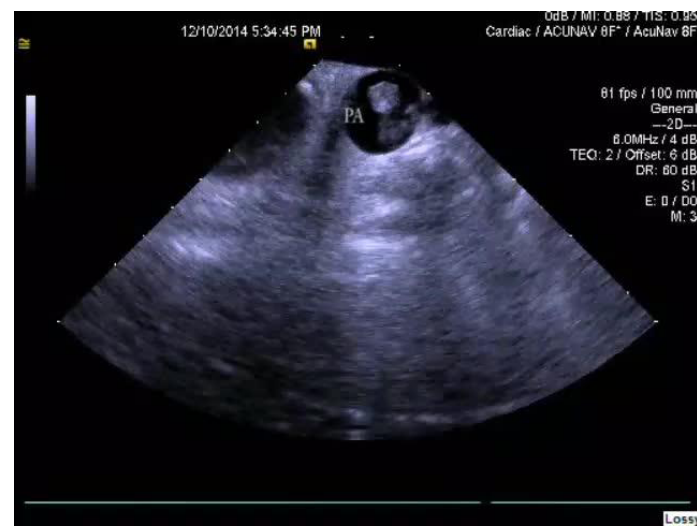

Video 1 Intracardiac echocardiogram revealing large thrombus involving the right atrium and left atrium as it straddles the PFO. PA, pulmonary artery.

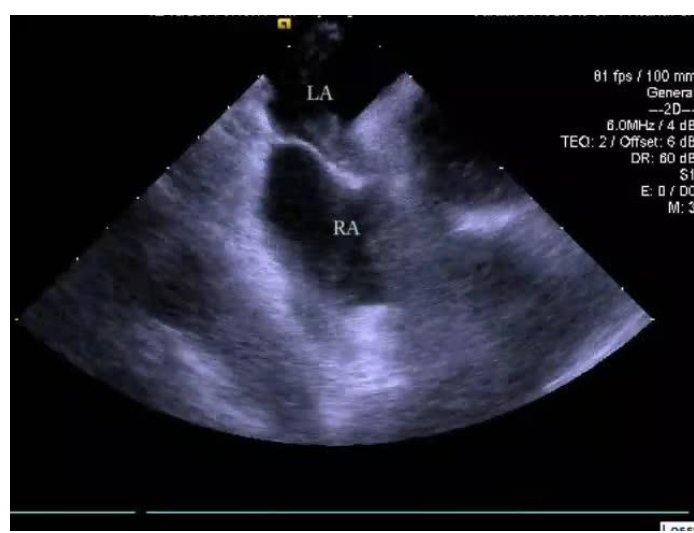

Video 2 Intracardiac echocardiogram revealing large thrombus extending into the left ventricle from the left atrium with each beat of the heart. LA, left atrium; RA, right atrium.

The following day, the patient was taken to the cardiac catheterisation laboratory for PFO closure. Intracardiac echocardiography revealed a large oscillating mass in the right atrium (video 1 ), right ventricle, left atrium (video 2) and pulmonary artery (video 3). Cardiothoracic surgery was emergently consulted.

Intracardiac surgery confirmed a biatrial thrombus straddling the PFO (TSPFO). An extensive main pulmonary artery clot was also discovered and removed. Pathology report revealed a $20.0 \times 1.0 \mathrm{~cm}$ intracardiac thromboembolic clot and a $2.5 \times 8.0 \times 1.0 \mathrm{~cm}$ pulmonary artery thromboembolic clot. Following the procedure, the

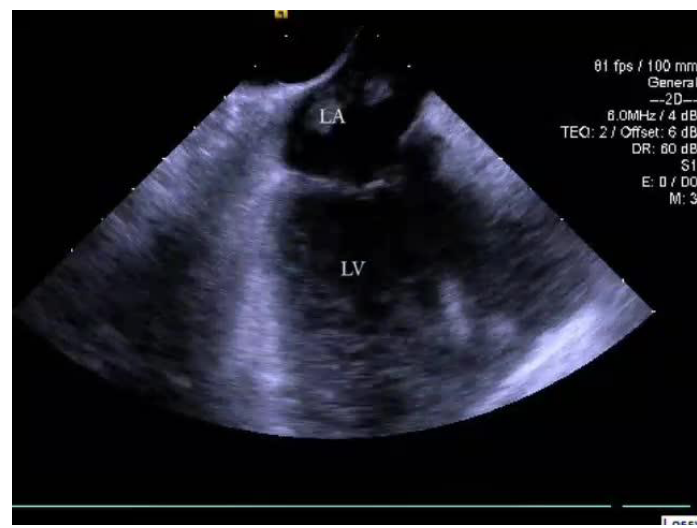

Video 3 Intracardiac echocardiogram revealing large thrombus involving the main pulmonary artery. 


\section{Learning points}

- The combination of a thrombus straddling a patent foramen ovale (PFO) and acute pulmonary embolism significantly increases the likelihood of the occurrence of a paradoxical embolism.

- Given the prevalence of PFOs, patients presenting with acute stroke should undergo a cardiac work-up to evaluate for paradoxical embolism as the underlying cause of stroke.

- Intracardiac echocardiography has extremely high sensitivity for identifying intracardiac masses that may not be appreciated by other forms of echocardiography.

patient's condition improved. He was eventually discharged to an extended care facility.

PFOs are common functional cardiac defects affecting approximately $27 \%$ of the population; however, they are generally benign entities. ${ }^{1}$ A feared, yet uncommon, sequela of PFOs is a paradoxical embolism (PDE), the result of embolic material travelling from venous to arterial circulation through an intracardiac shunt. ${ }^{1}$ Passage of an embolus through a PFO is far more common than a TSPFO. TSPFO may be associated with a pulmonary embolism (94\%) or, less commonly, a PDE (44\%). ${ }^{2}$ In the presence of massive PE, the risk of PDE increases due to the transient increase in right atrial pressure. ${ }^{3}$ As was the case in this patient, both may be implicated. Expedient diagnosis and treatment of TSPFO is imperative, as the mortality rate of impending
PDE may be as high as $21 \% .{ }^{1}$ Given the high prevalence of PFOs, patients presenting with stroke should undergo a work-up that includes a TTE to evaluate for congenital cardiac defects. ${ }^{1}$ Due to the rarity of TSPFO, optimal treatment is not well established. Treatment modality, selected based on thrombus severity, patient comorbidities and risk for PDE, may be medical (ie, heparin, thrombolysis) or surgical. ${ }^{2}$

Contributors RD was a medical student in the cardiac intensive care unit (ICU) and took care of the patient during his admission. She prepared the manuscript which was edited and approved by all authors. JD was a medical student in the cardiac ICU and took care of the patient during his admission. MA was a fellow taking care of the patient during the admission discussed in the case. He participated in the cardiac intervention and was directly involved in his care. YA was a fellow taking care of the patient during the admission discussed in the case. He performed echocardiograms and was directly involved in his care.

Funding The authors have not declared a specific grant for this research from any funding agency in the public, commercial or not-for-profit sectors.

Competing interests None declared.

Patient consent Obtained.

Provenance and peer review Not commissioned; externally peer reviewed.

\section{REFERENCES}

1 Fauveau $\mathrm{E}$, Cohen A, Bonnet $\mathrm{N}$, et al. Surgical or medical treatment for thrombus straddling the patent foramen ovale: impending paradoxical embolism? Report of four clinical cases and literature review. Arch Cardiovasc Dis 2008;101:637-44.

2 Nemoto A, Kudo M, Yamabe K, et al. Successful surgical treatment for a thrombus straddling a patent foramen ovale: a case report. J Cardiothorac Surg 2013;8:138.

3 Zoltowska DM, Agrawal Y, Gupta V, et al. Massive thrombus trapped within an atrial septal defect. BMJ Case Rep 2018;2018:bcr-2018-225647.

Copyright 2018 BMJ Publishing Group. All rights reserved. For permission to reuse any of this content visit

http://group.bmj.com/group/rights-licensing/permissions.

BMJ Case Report Fellows may re-use this article for personal use and teaching without any further permission.

Become a Fellow of BMJ Case Reports today and you can:

- Submit as many cases as you like

- Enjoy fast sympathetic peer review and rapid publication of accepted articles

- Access all the published articles

- Re-use any of the published material for personal use and teaching without further permission

For information on Institutional Fellowships contact consortiasales@bmjgroup.com

Visit casereports.bmj.com for more articles like this and to become a Fellow 